\title{
Información para los autores
}

\section{Normas para la remisión de artículos}

Los artículos propuestos para la revista, pueden subirse a la plataforma Open Journal System a través del siguiente enlace:

$$
\text { http://revistas.pedagogica.edu.co/index.php/TED }
$$

O también pueden ser enviados a las siguientes direcciones de correo electrónico:

revistated.fct@gmail.com revistated@pedagogica.edu.co

Para la remisión de artículos se deben tener en cuenta las siguientes consideraciones:

1. El artículo se presenta en formato .docx (Word 2010 o superior) en tamaño carta, con márgenes superior e inferior de $2.5 \mathrm{~cm}$ y márgenes derecho e izquierdo de $3 \mathrm{~cm}$. Encabezado 1,4 cm. Pie de página 1,25 $\mathrm{cm}$. La extensión máxima del documento es de 20 folios, incluyendo referencias bibliográficas.

2. Todo el texto debe estar en fuente Times New Roman 12 puntos, color negro, interlineado de 1,5 y sin estilos. Entre párrafo y párrafo se debe dejar un espacio, así como entre título y párrafo. No se admiten textos en altas en ninguna parte del documento (mayúsculas sostenida). Los Títulos deben estar en negrilla y los subtítulos en negrilla e itálica.

La numeración y el título de tablas, diagramas, gráficas, imágenes y fotografías, deben ir debajo de estos, con alineación centrada y en fuente Times New Roman 10 puntos. El texto de los primeros párrafos debe encontrarse sin sangría, y después de este, se configura cada párrafo con sangría de 1 en la primera línea.

3. Las tablas, diagramas y gráficas deben realizarse en Word o Excel y estar numeradas, citadas e incluidas en el documento. Los textos de los esquemas deben estar digitados en Word y no como formato de imagen.

4. Las Imágenes, fotografías y mapas, deben entregarse en archivos independientes, con los nombres correspondientes y en formato TIF o JPEG, ya sea en una resolución de alto pixelaje (4608×3072px) o de 300 ppp, 
con un ancho de $16 \mathrm{~cm}$ y en color original. Deben ir enumeradas e incluidas en el documento.

5. Las notas de pie de página tendrán una secuencia numérica; se debe procurar que sean pocas y escuetas, y realizarse sólo para aclaraciones del texto más no para citar libros. Los libros consultados solo estarán en las referencias bibliográficas.

6. Las citas y referencias bibliográficas deben presentarse con la norma APA (American Psychological Association) vigente.

7. Se deben enviar dos copias del documento, una que contenga la información completa de los(as) autores(as) tal como: (Documento 1), y otro, en la que no debe hacerse alusión a los(as) autores(as) del mismo (Documento 2), el nombre de ambos documentos es el título del artículo, diferenciados por el número 1 y 2.

8. El artículo debe estructurarse de acuerdo con los modelos de remisión otorgados por la revista acorde a las tres modalidades de presentación (Artículo de Investigación, Reflexión o Reporte de Caso Educativo), los cuales se encuentran en el Open Journal System o en la información para autores de cada edición, allí se indica, que posterior al encabezado inicial, los(as) autores(as) deben indicar a qué tipo de artículo corresponde su documento.

9. El contenido de los artículos es de exclusiva responsabilidad de los(as) autores(as), quienes envían una carta con la Declaración ética y Cesión de derechos patrimoniales, según el formato establecido por la revista, quien se reserva el derecho de publicación de los artículos propuestos. Sin esta carta, no se inicia el proceso editorial.

10. Los(as) autores(as) del documento diligencian su hoja de vida sintetizada en un formulario de google dispuesto para tal fin, en el que se precisa, formación académica, filiación institucional, publicaciones recientes en revistas o libros, experiencia docente e investigativa. 


\section{》) Procesos de revisión por pares}

Antes de remitir el artículo a la revisión de los(as) árbitros, el documento es evaluado por el equipo de apoyo técnico editorial para verificar la temática y el cumplimiento de los requisitos dados a los(as) autores(as), este proceso de evaluación preliminar se realiza en un periodo de dos (2) semanas y los ajustes iniciales son realizados por los(as) respectivos(as) autores(as) para asignar de esta manera pares académicos especializados en el tema y de la misma área de los(as) autores(as), para emitir los respectivos conceptos.

El criterio de arbitraje de los artículos en TED, se hace a partir del sistema de revisión por pares teniendo en cuenta los siguientes aspectos:

1. Protección de la identidad de los pares evaluadores y de los autores.

2. El tiempo de evaluación de los artículos se hace entre 4 y 8 meses.

3. Los artículos se someten al mecanismo de evaluación a ciegas. Para ello, al momento de enviar a evaluar el artículo, el documento no cuenta con los nombres de los(as) autores(as), así como la información que los pueda identificar.

4. Los artículos se someten a dos árbitros expertos para emitir su concepto. Si hay contradicción entre los dos conceptos, el artículo se somete a un(a) tercer evaluador(a).

5. Los árbitros diligencian el formulario virtual de evaluación en donde registran su concepto, sus observaciones y determina:

- Aceptar la publicación sin modificaciones

- Aceptar la publicación con modificaciones

- No aceptar la publicación.

6. El comité editorial aprueba la publicación de los artículos de acuerdo con el proceso y resultado del arbitraje.

7. El resultado del proceso de evaluación es inapelable en todos los casos 


\section{1) Tipología de artículos
en la revista TED}

A continuación se presentan los tipos de artículos que se reciben, para publicación en la revista TED.

\section{Artículo de investigación en educación en ciencias experimentales, matemáticas y tecnologías}

- Documento original e inédito que presenta de manera detallada, alguno de los siguientes aspectos:

- Resultados de investigación surgidos en el desarrollo de tesis de maestría, doctorado $u$ otras investigaciones (financiadas o no).

- Investigaciones documentales o tipo de estado de arte, sobre un tema que aporta al desarrollo de investigaciones y propuestas de enseñanza/ aprendizaje, para la Educación en Ciencias Experimentales, Matemáticas y Tecnología.

\section{Artículo de reflexión o ensayo}

- Documento original e inédito donde se analizan, sistematizan e integran reflexiones desarrolladas en una temática particular de la Educación en Ciencias Experimentales, Matemáticas y Tecnología, con el fin de dar cuenta de avances y tendencias. Se caracteriza por presentar una cuidadosa revisión bibliográfica de por lo menos 50 referencias.

\section{Reporte de caso educativo}

- Documento original e inédito que presenta la sistematización de experiencias escolares y propuestas de enseñanza relacionadas con la Educación en Ciencias Experimentales, Matemáticas y Tecnología

\section{Editorial}

- Documento escrito por el editor, un miembro del comité editorial o un investigador invitado sobre orientaciones en el dominio temático de la edición de la revista

\section{Traducción}

- Traducciones de artículos de interés particular en el dominio de publicación de la edición de la revista. 


\section{\) Estructura de remisión de artículos}

A continuación se presenta la estructura de remisión para artículos de la revista en sus tres modalidades, para todos los casos se cuenta con un encabezado general y de acuerdo al tipo de artículo se desarrollan unas secciones específicas.

\begin{tabular}{|c|c|c|c|c|c|}
\hline \multicolumn{6}{|c|}{ ENCABEZADO GENERAL PARA TODOS LOS TIPOS DE ARTÍCULO } \\
\hline \multicolumn{6}{|c|}{ TITULO EN ESPAÑOL } \\
\hline \multicolumn{6}{|c|}{ TÍTULO EN INGLÉS } \\
\hline \multicolumn{6}{|c|}{ TÍTULO EN PORTUGUÉS } \\
\hline \multicolumn{6}{|c|}{ Nombres y Apellidos completos del autor principal ${ }^{1}$} \\
\hline \multicolumn{6}{|c|}{ Nombres y Apellidos completos del co-autor ${ }^{2}$} \\
\hline \multicolumn{6}{|c|}{ Nombres y Apellidos completos del co-autor ${ }^{3}$} \\
\hline \multicolumn{6}{|c|}{ Resumen } \\
\hline \multicolumn{6}{|c|}{ Palabras clave. } \\
\hline \multicolumn{6}{|c|}{ Abstract } \\
\hline \multicolumn{6}{|c|}{$\begin{array}{c}\text { Resumo } \\
\text { Palavras chaves. }\end{array}$} \\
\hline \multicolumn{2}{|c|}{$\begin{array}{l}\text { ESTRUCTURA ARTÍCULO } \\
\text { DE INVESTIGACIÓN. }\end{array}$} & \multicolumn{2}{|r|}{$\begin{array}{l}\text { ESTRUCTURA REPORTE } \\
\text { DE CASO EDUCATIVO }\end{array}$} & \multicolumn{2}{|r|}{$\begin{array}{c}\text { ESTRUCTURA ARTÍCULO } \\
\text { DE REFLEXIÓN }\end{array}$} \\
\hline 1 & Introducción & 1 & Introducción & 1 & Introducción \\
\hline 2 & Antecedentes & 2 & $\begin{array}{c}\text { Fundamentación de la } \\
\text { Experiencia }\end{array}$ & \multirow[t]{2}{*}{2} & \multirow{2}{*}{ Tesis y Argumentos } \\
\hline 3 & Marco Teórico & 3 & Descripción de la Experiencia & & \\
\hline 4 & Metodología & \multirow{2}{*}{4} & \multirow{2}{*}{$\begin{array}{c}\text { Sistematización y análisis de } \\
\text { la experiencia }\end{array}$} & 3 & Conclusiones \\
\hline 5 & Resultados y Análisis & & & 4 & \multirow{2}{*}{ Referencias Bibliográficas } \\
\hline 6 & Conclusiones & 5 & Consideraciones Finales & 5 & \\
\hline 7 & Referencias bibliográficas & 6 & Referencias bibliográficas & 6 & \multirow{2}{*}{ Forma de citar el artículo } \\
\hline 8 & Forma de citar el artículo & 7 & Forma de citar el artículo & 7 & \\
\hline
\end{tabular}

1. Nivel de formación, filiación institucional, cargo, país, ciudad, correo electrónico y perfil ORCID

2. Nivel de formación, filiación institucional, cargo, país, ciudad, correo electrónico y perfil ORCID

3. Nivel de formación, filiación institucional, cargo, país, ciudad, correo electrónico y perfil ORCID 


\section{1) Formato declaración ética y cesión
de derechos patrimoniales}

Tecné, Episteme y Didaxis (TED) como revista científica, se ha comprometido a mantener altos estándares de publicación y, en consecuencia, toma todas las medidas necesarias para evitar las faltas a la ética en sus publicaciones. En este sentido a continuación se presenta el formato de declaración ética y cesión de derechos patrimoniales a enviar por parte de los(as) autores(as) al momento de remitir sus documentos a la revista.

\section{Declaración ética de los autores}

Mediante la presente doy fe que el trabajo titulado: que presento para posible publicación en la Revista Tecné, Episteme y Didaxis: TED, de la Facultad de Ciencia y Tecnología de la Universidad Pedagógica Nacional, no ha sido publicado en ninguna de sus versiones. Me comprometo a no someterlo en consideración de otra publicación mientras esté en proceso de evaluación en la Revista TED, ni posteriormente, en caso de ser aceptado para publicación.

Declaro que el artículo es original, ya que su contenido es producto de mi (o nuestra) autoría intelectual. Todos los datos y las referencias citadas de otras publicaciones han sido identificados con su respectivo crédito e incluidos en la bibliografía, en los casos que así lo requieran, cuento con las debidas autorizaciones de quienes poseen los derechos patrimoniales.

De acuerdo con lo anterior, declaro que todos los materiales que se presentan están totalmente libres de derechos de autor y por lo tanto, me hago responsable de cualquier litigio o reclamación relacionada con derechos de propiedad intelectual, exonerando de responsabilidad a la Universidad Pedagógica Nacional.

\section{Cesión de Derechos Patrimoniales}

Si el artículo es aprobado para su publicación, transfiero los derechos patrimoniales de este a la Universidad Pedagógica Nacional, para que incluya dicho texto en la Revista Tecné, Episteme y Didaxis: TED y pueda reproducirlo, editarlo, distribuirlo, exhibirlo y comunicarlo en Colombia y fuera de este país por medios impresos, electrónicos, Internet o cualquier otro medio conocido o por conocer, reconociendo los derechos de autor. 
Para constancia, se firma esta declaración a los días, del mes de del año , en la ciudad(es) , en el país

\begin{tabular}{l|l|l}
\hline Nombre & Firma & Documento de Identificación \\
\hline & & \\
\hline & & \\
\hline & & \\
\hline
\end{tabular}




\section{\) Evaluadores de artículos Tecné, Episteme y Didaxis: TED, No. 40}

\section{Arbitros nacionales}

OTTO LEONARDO GOMEZ HUERTAS

Magíster en Enseñanza de las ciencias naturales, Universidad Pedagógica Nacional.

Universidad Pedagógica Nacional, Docente del departamento de Tecnología.

Colombia, Bogotá

ogomez@pedagogica.edu.co

Orcid. Org/0000-0002-9218-5270

\section{JUAN DAVID ADAME}

Magister en Docencia de la Química, Universidad Pedagógica Nacional.

Estudiante doctorado interinstitucional en educación - énfasis educación en ciencias, Universidad Distrital Francisco José de Caldas - DIE-UD

Fundación Universitaria del Área Andina, departamento de ciencias básicas, docente e investigador

Colombia, Bogotá

bioadame@gmail.com

orcid.org/0000-0001-5626-0694

DIANA LINETH PARGA LOZANO

Magister en Docencia de la Química, Universidad Pedagógica Nacional

Estudiante Doctorado Universidade Estadual Paulista Júlio De Mesquita Filho

Doutorado em Educação em ciencias

Universidad Pedagógica Nacional, Docente

departamento de Química

Colombia, Bogotá

dianaparga@gmail.com

orcid.org/0000-0002-7899-0767

YINI CARDENAS

Magister en Docencia de la Química, Universidad Pedagógica Nacional

Universidad Manuela Beltrán Unidad Virtual,

Coordinadora de Investigación

Colombia, Bogotá

yipacaro22@gmail.com

orcid.org/0000-0002-6841-6825

\section{YAIR ALEXANDER PORRAS CONTRERAS}

Magister en Docencia de la Química, Universidad Pedagógica Nacional

Universidad Pedagógica Nacional, Docente

departamento de química.

Colombia, Bogotá

yairporras@gmail.com

orcid.org/0000-0002-7111-0632
FRANCISCO JAVIER CAMELO

Magister en Docencia de la Matemática,

Universidad Pedagógica Nacional

Universidad Distrital Francisco José de Caldas,

Docente de Educación Matemática

Colombia, Bogotá

ficamelob@gmail.com

Orcid.org/0000-0002-8627-4816

DIANA FABIOLA MORENO SIERRA

Doctora en Educación en Ciencias, Universidade Estadual Paulista UNESP

Universidad Distrital Francisco José De Caldas,

Docente

Colombia, Bogotá.

diana.educi@gmail.com

orcid.org/0000-0002-5515-7609

JIMMY WILLIAM RAMÍREZ CANO

Magister en Ingeniería de Telecomunicaciones, Universidad Nacional de Colombia Universidad Pedagógica Nacional, Docente

Departamento de Tecnología

Colombia, Bogotá.

jrbacano@gmail.com

orcid.org/0000-0003-1435-0979

\section{ROYMAN PÉREZ MIRANDA}

Magister En Docencia de La Química.

Universidad Pedagógica Nacional

Universidad Pedagógica Nacional, Profesor del

Departamento de Química Colombia, Bogotá royman2004@hotmail.com

\section{DIEGO FABIAN VIZCAINO AREVALO}

Doutor em Educação para a Ciência, UNESP

Bauru

Universidad La Gran Colombia, Docente

Investigador. Colombia, Bogotá

d vizcaino@yahoo.com

orcid.org/0000-0001-5112-9646 


\section{Arbitros internacionales}

LINA VIVIANA MELO NIÑO

PhD. Science Education

Departamento de Didáctica de las Ciencias

Experimentales y las Matemáticas. Universidad de Extremadura.

España, Badajoz.

lina.viviana.melo@gmail.com

Orcid.org/0000-0003-4771-058X

ANA MARIA DE ANDRADE CALDEIRA

Programa de Pós-graduação em Educação para Ciência, Universidade Estadual Paulista "Júlio de Mesquita Filho

Universidade Estadual Paulista Júlio de Mesquita Filho, Professor Adjunto

Brasil, Bauru, São Paulo.

anacaldeira@fc.unesp.br

\section{CRISTINA ISABEL CONCHINHA}

Maestría en educación en la especialidad de educación y TIC, Universidade de Lisboa

Finalista del doctorado en la especialidade de ciências da educação na especialização de tecnologias, redes e multimédia na educação e formação, Universidade Nova de Lisboa Ministerio de Educación y Ciencia, Profesora de TIC y robotica educativa

Portugal, Lisboa

cristina_conchinha@hotmail.com

orcid.org/0000-0002-9306-5721

LAÍSA MARIA FREIRE DOS SANTOS

Doutor em Educação em Ciências e Saúde

Universidad Federal do Rio de Janeiro

Universidad Federal do Rio de Janeiro, Profesor

universitário

Brasil, Rio de Janeiro.

laisa@biologia.ufri.br

orcid.org/0000-0002-4573-0969

\section{UBIRATAN D'AMBROSIO}

Doctor en Matemáticas, Universidade de Sao paulo Universidade Estadual de Campinas, Professor Brasil, São Paulo.

ubi@usp.br
CLAUDIO AGUAYO CORVALÁN

Biólogo - Universidad de Chile

$\mathrm{PhD}$ in Education - Waikato University, New Zealand

Research assistant at the Centre for Learning and Teaching (CfLAT), Auckland University of Technology

Suiza, New Zealand

claudioaguayoc@gmail.com

PEDRO GUILHERME ROCHA DOS REIS

Doctor en Didáctica de las Ciencias, Universidad de Lisboa

Instituto de Educación de la Universidad de

Lisboa, Profesor

Portugal, Lisboa

preis@ie.ulisboa.pt

orcid.org/0000-0002-9549-2516

FERNANDA DA ROCHA BRANDO

Doutora em Educação para a Ciência

Professora Doutora, do Departamento de Biologia da Faculdade de Filosofia, Ciências e letras de Ribeirão Preto de Universidade de São Paulo. (FFCLRP-USP)

Brasil, São Paulo.

ferbrando@ffclrp.usp.br

MARIA CRISTINA PANSERA DE ARAÚJO

Doutorado em Genética e Biologia Molecular, UFRGS, Rio Grande do Sul

Universidade Regional do Noroeste do Estado do Rio Grande do Sul - Unijui. Professora

Brasil, liuí-Rio Grande del Sur.

pansera95@gmail.com

orcid.org/0000-0002-2380-6934 
Editado en 2016

Se compuso de caracteres Futura Lt BT y Futura Bk a 11 pts y se imprimió sobre papel propalcote de 75 gramos, con un tiraje de 250 ejemplares

Bogotá, D.C. Colombia

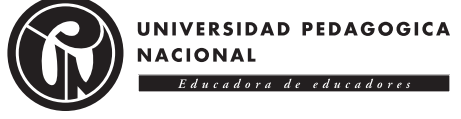

Universidad Pedagógica Nacional Educadora de educadores

http://www.pedagogica.edu.co/revistas/ojs/index.php/TED 